This item was submitted to Loughborough's Research Repository by the author.

Items in Figshare are protected by copyright, with all rights reserved, unless otherwise indicated.

\title{
I-challenges: influencing others' perspectives by mentioning personal experiences in therapeutic community group meetings
}

\section{PLEASE CITE THE PUBLISHED VERSION}

https://doi.org/10.1177/0190272517706048

\section{PUBLISHER}

SAGE @ American Sociological Association

\section{VERSION}

AM (Accepted Manuscript)

\section{PUBLISHER STATEMENT}

This work is made available according to the conditions of the Creative Commons Attribution-NonCommercialNoDerivatives 4.0 International (CC BY-NC-ND 4.0) licence. Full details of this licence are available at: https://creativecommons.org/licenses/by-nc-nd/4.0/

\section{LICENCE}

CC BY-NC-ND 4.0

\section{REPOSITORY RECORD}

Pino, Marco. 2017. "I-challenges: Influencing Others' Perspectives by Mentioning Personal Experiences in Therapeutic Community Group Meetings”. Loughborough University. https://hdl.handle.net/2134/24730. 


\title{
I-challenges: Influencing Others' Perspectives by Mentioning Personal Experiences in Therapeutic-Community Group Meetings
}

\author{
Marco Pino \\ Loughborough University
}

\begin{abstract}
In this paper I examine the communicative practice of mentioning a personal experience as a vehicle for challenging a peer's perspective. I study this in the context of Therapeutic Community (TC) group meetings for clients recovering from drug misuse. Using conversation analysis, I demonstrate that TC clients use this practice, which I call an I-challenge, to influence how their peers make sense of their own experiences, and to do so without commenting on those peers' experiences and perspectives.

This study highlights the power of talking in the first person as a means of influencing others-a notion previously made popular by Thomas Gordon's work on 'I-messages'. Additionally, this study illustrates a novel way of studying social influence. Whereas previous research in social psychology has focused on the cognitive constraints behind phenomena of social influence and persuasion, here I contribute towards understandings of the interactional norms underlying the organisation of influence as a structured and coordinated domain of social action.
\end{abstract}

\section{Keywords}

conversation analysis, addiction, experience, group, social influence 
Pino, M. (2017). I-challenges: Influencing Others' Perspectives by Mentioning Personal Experiences in Therapeutic-Community Group Meetings. Social Psychology Quarterly, 80(3), 217-242.

In this article, I examine a communication practice used to influence others' perspectives by mentioning one's own personal experience. Through this practice, which I call an I-challenge, people can influence others without directly commenting on their experiences and perspectives. I examine this phenomenon in the context of group meetings within therapeutic community (TC) programs for clients undergoing treatment for drug misuse.

The practice of influencing others by mentioning a personal experience has been previously described in Thomas Gordon's popular theory of I-messages, originally formulated with reference to parenting (Gordon 1970) and teaching (Gordon [1974] 2003). Gordon proposed that I-messages (statements about the speaker) should be preferred over youmessages (statements about the recipient) for influencing others' behaviors. Examples of youmessages in teaching are orders ("You stop that!") and criticism ("You're not thinking maturely"; Gordon [1974] 2003:132-33). I-messages are statements that "reveal something about the teacher," for example "I'm frustrated by the noise" (Gordon [1974] 2003:132-33). These would allow one to influence others' behaviors without commenting on their conduct.

Gordon's theory is somewhat silent to how exactly you- and I-messages work. He posited that recipients can detect hidden messages embedded in you-messages, such as "I am the boss, the authority" or "You're too dumb to figure out how to help me" (Gordon [1974] 2003:132-33); on this basis, recipients would treat you-messages as unauthentic, damaging, and manipulative. By contrast, recipients would react positively to I-messages because these would convey authentic information about the speaker. One problem with these arguments is that they are not grounded on observational evidence on how people construct and recognize you-/I-messages in their naturally occurring interpersonal interactions. Additionally, Gordon's notion of "message" does not indicate what action would constitute the unit of analysis (Schegloff 1988). It reflects the dominance of an information-transmission model of communication prevalent at the time and therefore does not take into consideration what we know now about the role of sequences of actions in the organization of interpersonal interactions (Heritage 2012; Schegloff 1990). Gordon's notion that recipients would find hidden messages in their interlocutors' talk also presents difficulties. People monitor others' talk in real time to recognize the actions that it implements (e.g., requests, invitations, challenges, etc.); they base these determinations on observable features of utterances - features that are therefore not "hidden" (Heritage forthcoming).

Additionally, Gordon suggested that you-/I-messages promote different types of social relationship, with you-messages promoting more authoritarian relationships and I-messages more democratic ones (Oryan and Gastil 2013). This was a significant intuition, proposing that 
people use different ways of talking - alternative types of utterance - to promote different types of social relationships in the moment-by-moment unfolding of their interpersonal interactions. However, Gordon's theory does not explain how people construct and recognize you-/I-messages as reflecting or promoting different types of social relationships.

In this article, I examine how TC clients use utterances referencing the self-what Gordon called I-messages - to challenge their peers. Compared to Gordon's prescriptive approach to recommending the use of I-messages, I take a descriptive/naturalistic approach by asking how people use I-messages in their naturally occurring interactions and what they accomplish through them. I concentrate on one particular action that TC clients implement through utterances referencing the self: challenging their peers' perspectives. ${ }^{1}$ Adapting Gordon's locution, I call this practice an I-challenge.

Using conversation analysis (Sidnell and Stivers 2013), I describe the procedures that TC clients use to construct and recognize utterances referencing the self as actions that challenge their peers' perspectives. Subsequently, I ask what motivates clients' use of Ichallenges and propose that through this practice, clients can handle a problem of experience that they regularly face when they challenge their peers. Finally, I discuss implications for social psychological notions of social influence. I propose that conversation analytic understandings of how people attempt to influence others can expand current views of social influence, which are mainly based on theories of how recipients cognitively process others' messages. My study findings cast new light on influence by identifying constraints informing the ways in which speakers design their actions; such constraints appear to be associated in primis with the very nature of the social activity in which speakers engage - challenging a peer's perspective - and the practical problems that it raises.

\section{Therapeutic Communities}

Therapeutic communities (TCs) are residential programs for drug addiction, within which staffled group meetings are a core component. A common activity is for clients to report on their recent experiences to the group (Pino 2016b). Through that process, they share their perspectives on a range of issues. Other group members - staff and clients - monitor clients' individual reports for signs of adherence to therapeutic principles, and they challenge clients' perspectives that contradict them. The TC approach encapsulates this process in the notion of “reality confrontation” (Campling 2001). In Rapoport's (1959:63) classic rendition, 
Reality-Confrontation refers to the Unit's [i.e., the TC's] belief that patients should be continuously presented with interpretations of their behavior as it is seen by most others. This is meant to counteract patients' tendencies to use massive denial, distortion, withdrawal, or other mechanisms that interfere with their capacity to relate to others in the normal world.

In more recent versions, emphasis is less on interpretations and more on members' reciprocal feedback on perspectives that might be dysfunctional or unhelpful for the therapeutic process (Shah and Paget 2006). According to the TC principle of "community as method" (Campling 2001), every member is expected to help with others' recovery; one way of doing this is for clients to challenge their peers' perspectives. I examine a practice - the I-challenge - that TC clients employ to implement the process of reality confrontation.

\section{Earlier Studies on Mentions of Personal Experiences}

In this article, I examine how TC clients challenge their peers through the practice of mentioning a personal experience. Relevant to the understanding of this phenomenon is prior research in conversation analysis, examining the use of stories and personal experiences. Sacks (1992) examined sequences of talk where a speaker tells a story and the next speaker tells a "second story" designed to display similarities to the first. Speakers design second stories to exhibit "experiential matching" (Heritage and Lindström 1998), for example, by reporting an experience in which they played a similar role to the first speaker in their own experience. Kendrick (2013) proposed that reciprocity is a fundamental organizational principle in social interaction. According to this principle, when someone reports a personal experience, they systematically provide interlocutors with an opportunity to reciprocate by reporting a similar experience. The idea of reciprocity offers a framework for considering the sequences examined in this article; it suggests that when a TC client shares an experience, other clients have an opportunity to share their own experience in ways that are relevant to the matter under discussion (Wootton 1977). Sharing experiences would be an available resource that clients can use for different interactional purposes.

Other research has examined actions that people implement by sharing their experiences. Second speakers report matching experiences to affiliate with first speakers 
Pino, M. (2017). I-challenges: Influencing Others' Perspectives by Mentioning Personal Experiences in Therapeutic-Community Group Meetings. Social Psychology Quarterly, 80(3), 217-242.

(Ruusuvuori 2005) or convey a sense of solidarity and support, such as in Alcoholics Anonymous (Arminen 2004). People also use personal experiences to depart from the perspective of a prior speaker. For instance, speakers can report an experience to indirectly offer a new understanding of the other's experience (Arminen 2004) or normalize the other's experience (Heritage and Lindström 1998; Leudar, Antaki, and Barnes 2006). In this study, I focus on how mentioning a personal experience can be used to depart from an interlocutor's perspective; through this practice, TC clients challenge-rather than share-their peers' perspectives.

Methods

Data was collected between 2009 and 2014 in three TCs in Italy; these were a residential TC for drug addiction, a residential TC for drug addiction and mental health issues, and a semiresidential TC for young adults with drug addiction. The TCs delivered intensive residential or semi-residential rehabilitation involving work, educational, and leisure activities. Meetings involving the clients and a number of staff members happened in each TC on a weekly basis. The staff members had a background in education, social work, or psychology. The clients had diagnoses of drug and/or alcohol addiction and sometimes mental health issues. The number of staff per meeting varied from 1 to 4 ; the number of clients from 3 to 16. Data consisted of 24 audio- or video-recorded meetings lasting 26 hours in total; the instances used in this article are from video-recorded meetings, with the exception of extracts 1 and 3.

My interest in I-challenges emerged within a broader examination of actions that TC clients implement by mentioning their experiences. Using conversation analysis (Sidnell and Stivers 2013), I collected and analyzed sequences in which clients mentioned personal experiences in response to another group member. I found 12 cases where clients mentioned their experiences in affiliative ways (supporting a peer's perspective), 21 cases where clients mentioned their experiences to challenge a generalizing statement, and 23 cases where clients mentioned their experiences to challenge a peer's perspective. Therefore, my approach was to collect instances of a practice and examine the actions it implements.

In this article, I examine the third set of practices, and I hope to examine the others in future reports. The target practice is not frequent. It occurs in nine recorded meetings, one to eight times per single meeting. Although it is difficult to explain the nonoccurrence of a practice, one possible reason for the relatively rare use of I-challenges is that the staff members mainly provide feedback on the clients' experiences and perspectives in the meetings - not the 
other clients. This may suggest that the $\mathrm{TC}$ members in my recordings do not employ, to its full potential, an interactional resource that is available to clients - the I-challenge.

The extracts in this article contain an idiomatic English translation of the original language (Italian). The full transcripts - including original Italian, interlinear gloss, and idiomatic translation - are reproduced in Online Appendix A. ${ }^{2}$ The transcription conventions are available on the American Sociological Association's website. ${ }^{3}$ Participants gave written informed consent for publishing the transcripts. Names in this article are pseudonyms. I refer to client $\mathrm{A}(\mathrm{Ca})$ as the client who conveys a perspective - subsequently challenged — and to client $\mathrm{B}(\mathrm{Cb})$ as the client who mentions a personal experience to challenge client $\mathrm{A}$ 's perspective.

\section{Results}

I-challenge is the interactional practice (Schegloff, 1997) of mentioning a personal experience to convey the action of challenging someone's perspective. Before introducing the distinctive features of I-challenges, I observe that clients also use the practice of mentioning their experience to share-rather than challenge-a peer's perspective. In extract 1, Lidia (client A) is recounting the time she disclosed her condition as a drug user to her parents (lines 1-5). Enrico (client B) issues an appreciative assessment (line 6), whose valence Lidia matches in a subsequent assessment (lines 7-8). In this context of established concordance, Enrico mentions he had an equivalent experience ("anche per me," literally translatable as "also for me," and translated as "for me too" in idiomatic English; line 11). He does not introduce his experience contrastively but in a way that conveys experiential matching (Heritage and Lindström 1998), specifically through the turn-initial "anche"/“also" (see Online Appendix A). I will show that clients implement I-challenges by commenting on their experience in a way that contrasts with how the other client has commented on their own experience. Also, they often mention that experience in the context of established nonconcordance between the clients' perspectives. ${ }^{4}$

(1) IntV4 15:07 'They have found out'

$$
\begin{aligned}
& \mathrm{Ca}=\text { client } \mathrm{A} \text { (Lidia) } \\
& \mathrm{Cb}=\text { client } \mathrm{B} \text { (Enrico) }
\end{aligned}
$$


Pino, M. (2017). I-challenges: Influencing Others' Perspectives by Mentioning Personal Experiences in Therapeutic-Community Group Meetings. Social Psychology Quarterly, 80(3), 217-242.

Staff $=$ Marta

01 Ca-lid: dopo: dieci minuti ho chiamato il paolo, e ho detto after ten minutes have-1S call-PSTP the NAME and have-1S say-PSTP after ten minutes I called Paolo, and I said

02

"Paolo, guarda io glielo dico perché $\uparrow q u a:$

NAME look-IMP.2S 1S.N 3P.D=3S.A say-1S because here

"Look Paolo, I'm telling them because

03

mi stanno facendo: heh <pressione, > e mi- C'han

1S.D stay-3P do-GER pressure and 1S.A 1P.A=have-3P

they are putting heh <pressure> on me here, and they

04

>cioè< ci han scope:rto, e non è che .h=.h=.h" (.)

I.mean 1P.A have-3P discover-PSTP and not be-3S that

$>$ I mean< they have found out about us, and it's not that $. h=. h=. h "($.

06 Cb-Enr:

tk Che situazione dimme:r[da.

what situation of =shit

tk What a shitty situation.

07 Ca-Lid:

[É Stato

be-3S be-PSTP

It was

08

treme: $\mathrm{n}[\mathrm{do}$.

terrible

horrible.

09 Cb-Enr:

[Vacca di'.
cow god
Holy shit.

10 S-Mar: M[m.

PTC

$\mathrm{Mm}$.

11 Cb-Enr: ->

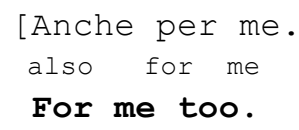


TC clients also implement challenges through practices other than mentioning their experience. In extract 2, the group members are discussing a phase in the therapeutic community (TC) program, which they call "the Test." The Test involves allowing a client to go home for a few days and then reviewing their experience when they come back to the $\mathrm{TC}$-for example, whether they have relapsed into drug use. Some clients have reported they felt no desire to use drugs during their Test. Others-including Gianni-have treated this as evidence of those clients' overconfidence and underestimation of their risk of relapsing (data not shown).

At lines 1-5, Gianni challenges the other clients' conveyed sense of security by proposing that they did not do "anything stupid"- that is, use drugs — during their Test only because their family members were closely monitoring them. With this, he implies that those clients are at risk of relapse. In contrast to I-challenges, Gianni does not implement his challenge by referring to his personal experience; he references a generic "you" (line 1) and thereby grounds his challenge on a general claim that applies to all the clients in the meeting. Other clients reject the applicability of that claim to their cases (lines 6-8). They exploit one feature of Gianni's challenge (lines 1-4): a claim about states of affairs in the other clients' lives, that is, matters over which they have more authoritative knowledge (Raymond and Heritage 2006). Later, Gianni switches to a different practice for implementing his challenge; he mentions that he had trouble during the Test (lines 28-32). This is an I-challenge. Crucially, by mentioning his difficulties, Gianni more cautiously grounds his challenge on a claim that is restricted to his experience, an area in which he has more authoritative knowledge.

(2) IntL4 1:25:19 'Monitored'

Clients: Gianni and a number of unidentified clients

Staff = Arianna

01 C-Gia: cioè è normale che le cavolate non le fai:

I.mean be-3S normal that the stupid.things not 3P.A do-2S

I mean it's normal that you don't do anything stupid

02

la prima volta. Né la seconda, (.) perché sei

the first time nor the second because be-2S

the first time. Or the second time, (.) because you are

03

guardato a vista, perché ti mettono alla

watch-PSTP at sight because 2S.A put-3S at=the

being watched, because they are putting you to the 
Pino, M. (2017). I-challenges: Influencing Others' Perspectives by Mentioning Personal Experiences in Therapeutic-Community Group Meetings. Social Psychology Quarterly, 80(3), 217-242.

04

$$
\begin{aligned}
& \text { pro[va. Lo } \uparrow \text { sai } \\
& \text { test } 3 \text {.A know-2S } \\
& \text { test. You } \uparrow \text { know that }
\end{aligned}
$$

05 Client:

06 Client:

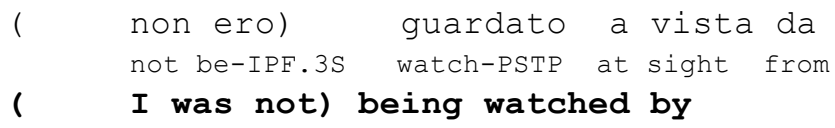

07

ne $[$ ssuno

nobody

anyone

08 Client:

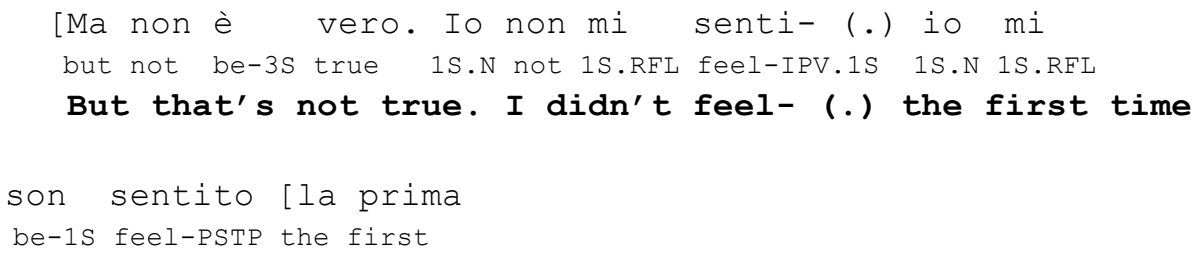

09 C-Gia:

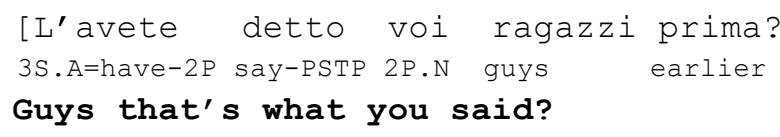

( . )

11 Client: No la prima [ ( )

no the first

No the first ( )

12 C-Gia:

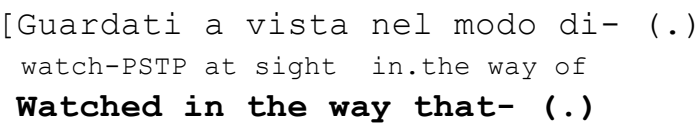

[ che

that

that

15 S-Ari: [Controllati. Insomma un po' controlled-P namely a bit Monitored. In other words a bit 
Pino, M. (2017). I-challenges: Influencing Others' Perspectives by Mentioning Personal Experiences in Therapeutic-Community Group Meetings. Social Psychology Quarterly, 80(3), 217-242.

18 Client:

[Ma io ( )

but 1S.N

But I ( )

19

la prima mi son sentito cosi. La seconda: : the first 1S.RFL be-1S feel-PSTP so the second

the first time I felt that way. The second time

mi son sentito a mio agio. Cioè da una parte.

1S.RFL be-1S feel-PSTP at my ease namely from one part

I felt comfortable. I mean in part.

21 C-Gia: Sì però ehyes but PTC

Yes but uh-

22 Client:
Io ero [lì (
IS.N be-IPF.1S there
I was there (
) a mangiare da mia madre.= to eat at my mother
) to have lunch at my mother's.=

23 C-Gia:

[Non lo so.
not 3S.A know-1S
I don't know.

24 Client: =E basta.

and enough

$=$ And that's it.

$($.

26 C-Gia:

Ma un qualcosa vi susciterà la Verifica.

but a something 2P.D raise-FUT.3S the Test

But the Test must do something to you.

27 Client: $\quad$ [Sì sì sì

yes yes yes

Yes yes yes

28 C-Gia:

[Che ne so. Io andavo a casa e lo

what DEM know-1S 1S.N go-IPF.1S to home and the

I don't know. I used to go home and

stare in famiglia con $i$ miei mi veniva

stay=INF in family with the mine-P 1S.D come-IPF.3S

staying with my family with my folks I used to get

l'ansia. Certe dinamiche mi veniva l'ansia. the=anxiety certain dynamics 1S.D come-IPF.3S the=anxiety

anxious. Some dynamics I used to get anxious.

Andare in centro in

go-INF in centre in 
Pino, M. (2017). I-challenges: Influencing Others' Perspectives by Mentioning Personal Experiences in Therapeutic-Community Group Meetings. Social Psychology Quarterly, 80(3), 217-242.

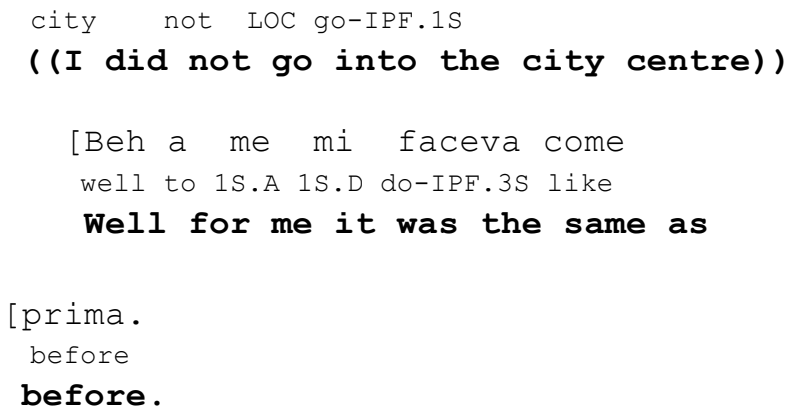

In what follows, I examine how clients construct and recognize I-challenges. Subsequently, I ask what drives clients' use of I-challenges and propose that this practice enables them to manage a fundamental problem of experience raised by the activity of challenging others.

\section{I-challenge as a Contrastive Perspective on a Shared Experience}

I examine sequences of talk where client A makes available their perspective on a personal event and subsequently client B mentions a personal experience. My goal in this section is to show how B constructs this turn to convey a challenge of A's perspective. Client B does so through two operations: (1) proposing that their own experience is relevantly similar to client A's experience-hence shared - and (2) conveying a perspective on that experience that radically differs from client A's perspective on their own experience. The first operation inferentially extends the applicability of B's perspective to A's case. Importantly, B does not make the link between the two experiences explicit; rather, they make it inferable through a syllogistic procedure (Gill and Maynard 1995; Pino 2016a). By establishing that their experience is relevantly similar to A's, B conveys that both clients' cases are instances of the same type of experience. When B comments on their own experience, A can infer that the same perspective applies to their own case. Since B's perspective radically differs from A's previously conveyed perspective, it effectively challenges it. B conveys the sense of an alternative and competitive perspective through the positioning of the turn within the unfolding activity and through its construction. In what follows, I provide two illustrative examples.

In extract 3, Lidia (client B) mentions her experience to challenge the self-serving character of Enrico's (client A) perspective about his own experience. Enrico is recounting that he used to hide his use of illegal drugs from his parents, the feelings associated with it, and that he decided to seek help at a support service. Enrico's claim that he wanted to stop using drugs is the target of Lidia's I-challenge (lines 17-21). Features of the context preceding Lidia's utterance support its understanding as a challenge. Lidia produces a "M:m" token (line 10) 
whose emphatic delivery makes it hearable as a negative reaction to Enrico's claim. She realizes it as a stretched " $\mathrm{m}$ "-sound with rise-fall intonation, which is perceptually distinct from the more punctual and high-pitched " $\uparrow \mathrm{Mm}$ " at line 5, hearable as a continuer. Enrico treats Lidia's "M:m" as a negative reaction to his claim by promptly amending it; he now claims that he did not want to quit using drugs "at first" (lines 13-14). By adjusting his earlier claim, Enrico displays an understanding that Lidia's reaction targets that part of his talk (lines 8-9). Therefore, Lidia subsequently mentions her experience (from line 17) in the context of already established nonconcordance with Enrico.

Other elements preceding Lidia's mention of her experience contribute to its understanding as a challenge. Lidia starts a turn with "guarda che"/“look" (line 15), a practice previously found to alert recipients to an upcoming redirection of the talk (Sidnell 2007). Here, it marks a departure from Enrico's perspective by introducing a competing view. Lidia then starts and abandons what looks like an incipient challenge; she is arguably on her way to claim that "most people" - that is, drug users - do not seek help because they want to stop using drugs. This foreshadows a departure from Enrico's claim that we wanted to quit using drugs; all the more so because it occurs after a troubles-telling, a place where affiliation is relevant (Jefferson 1988). ${ }^{5}$

(3) IntV4:550 28:25 'Quitting'

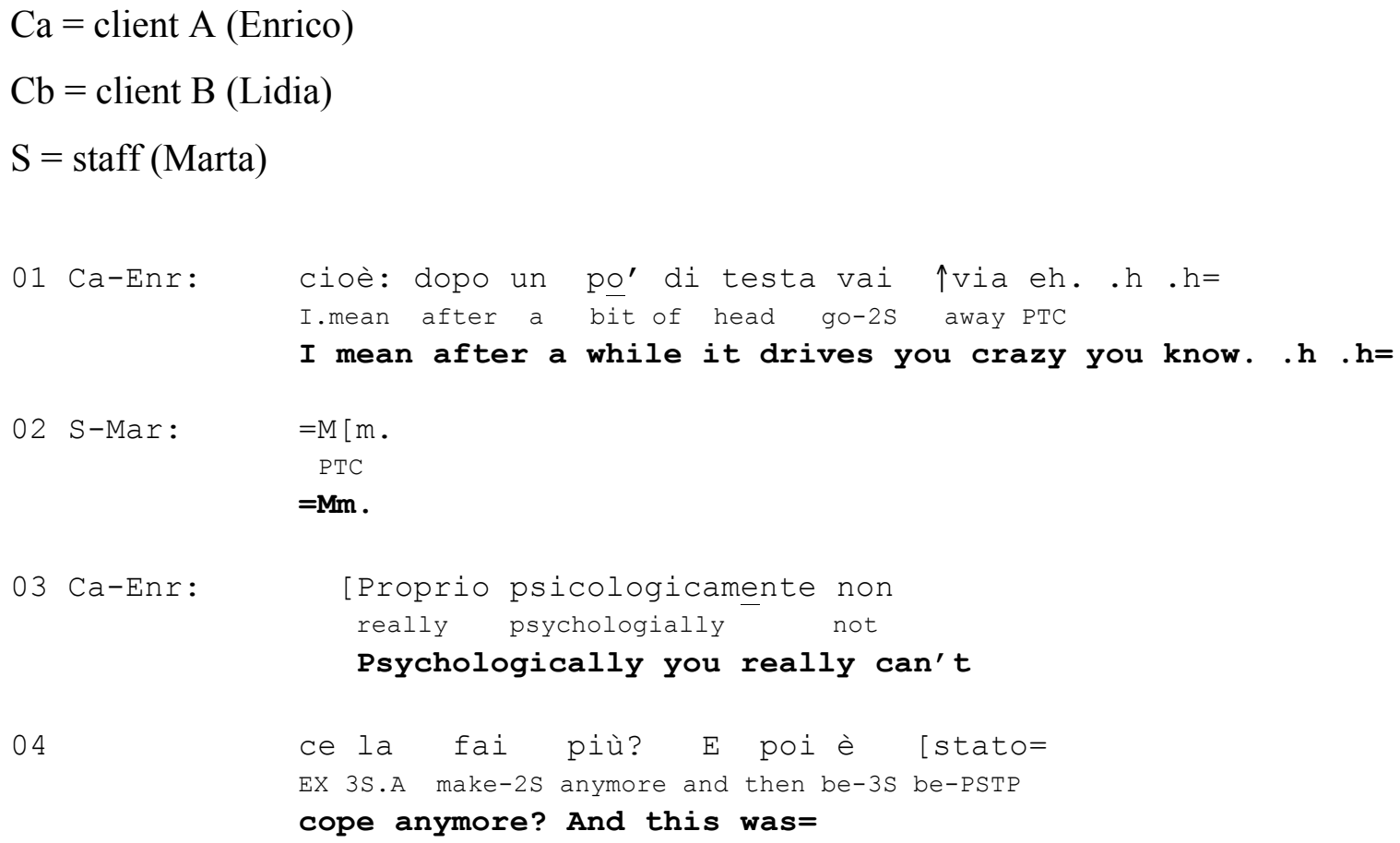


Pino, M. (2017). I-challenges: Influencing Others' Perspectives by Mentioning Personal Experiences in Therapeutic-Community Group Meetings. Social Psychology Quarterly, 80(3), 217-242.

$05 \mathrm{Cb}-\mathrm{Lid}$ :

$[\uparrow \mathrm{Mm}$

PTC

$\uparrow \mathrm{Mm}$

06 Ca-Enr: =per quello, che: .hhhh poi mi sono

for that CMP then RFL-1S be-1S

=the reason why .hhh later I

07

iscritto al Se:rT per: : : : (1.3)

register-PSTP at=the $\overline{\mathrm{NAME}}$ for

registered with the Se:rT because (1.3)

$(($ SerT $=$ addiction support centre $))$

08

tkl cioè per comunque cercare di

I.mean for anyway seek-INF to

tkl I mean anyway to try to

09

sme:ttere: : .

quit-INF

qui : $t$.

$10 \mathrm{Cb}-\mathrm{Lid}: \quad \mathrm{M}: \mathrm{m}$

$\overline{\mathrm{PTC}}$

$\underline{\mathrm{M}}: \mathbf{m}$.

11 Ca-Enr: .hhh $[\mathrm{h}$

12 Cb-Lid:

[. hhhhh

13 Ca-Enr:

$\uparrow \frac{\mathrm{S} I}{\text { yes }} \frac{\mathrm{NO}}{\mathrm{no}}$

个ES NO:

14

$\mathrm{BE}\left[: \mathrm{H} A \mathrm{~L}^{\prime} \mathrm{I}\right.$ ALL'INIZIO no.

well at=the at=the=beginning no

WE:LL NOT AT F NOT AT FIRST.

15 Cb-Lid:

$\begin{array}{llllll}\text { [GUARDA } & \text { CHE } & \text { LA MAGGIOR PARTE } & \text { DELLE } & \text { PER]SONE: (.) } \\ \text { look-IMP.2S } & \text { that the major } & \text { part of=the persons }\end{array}$

LOOK MOST PEOPLE (.)

16 Ca-Enr: [all'inizio no.]

at=the=start no

not at first.

17 Cb-Lid: -> [>(e) anch'io mi son isc]ritta al serT

(and) also=1S.N RFL-1S be-1S register-PSTP at=the NAME

$>$ (and) I also registered with the SerT 


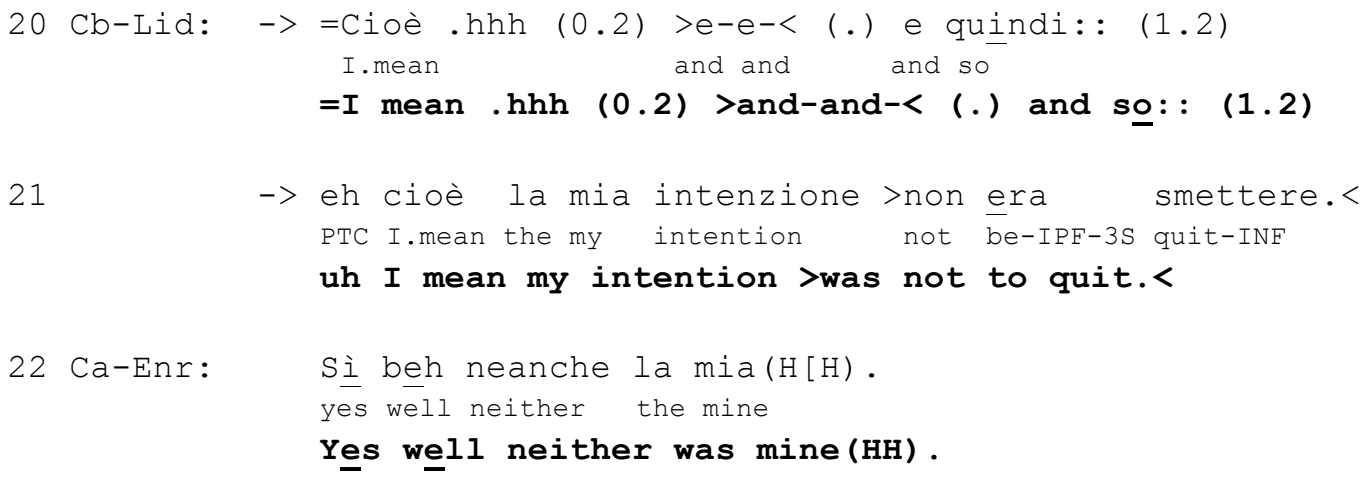

Two operations embodied in Lidia's utterance at lines 17-18 and 20-21 make it recognizable as challenging Enrico's perspective. First, Lidia claims that her experience was relevantly similar to Enrico"s (Arminen 2004; Wootton 1977); she "also" went to the local support center (lines 17-18). Second, in contrast to extract 1, Lidia comments on her experience in radically different terms than Enrico has done with his own. Her motivation for seeking help was "not" to quit (lines 20-21). Unlike extract 2, lines 1-4, where a client bases a challenge on a general claim, Lidia only comments on her own experience (lines 20-21) after establishing it is similar to Enrico's (lines 17-18). This operation extends the applicability of her perspective to Enrico's case, and since her perspective radically differs from his, it challenges it.

Enrico's admission that he also did not intend to quit (line 22) supports this analysis. He treats Lidia's mention of her experience as making relevant a revision of the way in which he has described his own experience. Additionally, his post-completion laughter particles (Schegloff 1996) convey a sense of admission, possibly displaying his understanding that Lidia has exposed the self-serving character of his self-description. I examine more evidence of recipients' displayed understandings of I-challenges in the next section.

In extract 4, Cristina (client B) mentions her experience to promote a more realistic or balanced representation of Mauro's (client A's) experience. Mauro has complained about withdrawal symptoms - he was a heroin user - and other clients have expressed doubts that his current physical problems are actually indicative of withdrawal (data not shown). At lines 13, Mauro complains about - and emphatically demonstrates by kicking the table — one of his alleged withdrawal symptoms: an involuntary movement of his leg. Describing nonordinary events, which disrupt the flow of the speaker's life, is a practice for constructing complaints (Drew 1998), which makes affiliation relevant (Drew and Walker 2009). At this sequential place, Cristina's articulation of a competitive perspective for the same type of experience conveys a challenge (line 7). 
Pino, M. (2017). I-challenges: Influencing Others' Perspectives by Mentioning Personal Experiences in Therapeutic-Community Group Meetings. Social Psychology Quarterly, 80(3), 217-242.

(4) IntV8:1864 32:10 'Twitches'

$$
\begin{aligned}
& \mathrm{Ca}=\text { client } \mathrm{A} \text { (Mauro) } \\
& \mathrm{Cb}=\text { client (Cristina) } \\
& \mathrm{C}=\text { other client (Carlotta) } \\
& \mathrm{S}=\operatorname{staff} \text { (Annamaria) }
\end{aligned}
$$

01 Ca-Mau:

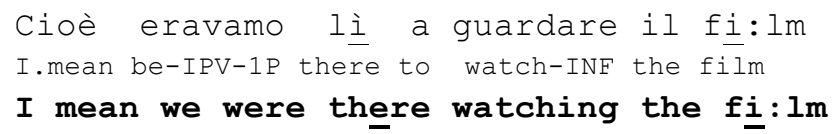


Pino, M. (2017). I-challenges: Influencing Others' Perspectives by Mentioning Personal Experiences in Therapeutic-Community Group Meetings. Social Psychology Quarterly, 80(3), 217-242.

\section{I-challenges as Attempts at Influencing Recipient Perspectives}

In this section, I demonstrate that client A (recipient of the I-challenge) observably treats client B's mention of their own experience as implementing a challenge. Client $\mathrm{A}$ - the recipient of the I-challenge - orients to the two constituent operations whereby client B (1) proposes their experience is relevantly similar to A's and (2) conveys a perspective on that experience that radically differs from A's perspective on their own experience. The evidence suggests that Ichallenges are sequence-initiating actions which make it relevant for recipients to modify the challenged perspective or alternatively, to further support it.

In what follows, I examine two classes of client responses. First, I examine responses whereby client A orients to both constituent operations of I-challenges: conveyed relevant similarity and competing perspective. These are further divided into responses whereby A modifies the challenged perspective, therefore embracing the alternative perspective conveyed with the I-challenge, and responses whereby A rejects the perspective conveyed through the Ichallenge, thereby maintaining the challenged perspective. Subsequently, I examine cases where A orients to the first constituent operation but not the second one. In these cases, A's orientation to the challenge-import of B's turn is less transparent. However, I propose that these responses still suggest that orientation based on a common feature they display; with these responses, A tests the relevant similarity of B's experience and their own.

Modifying the challenged perspective. This is the first type of response displaying an orientation to both constituent operations of I-challenges. In extract 3, Enrico's responses are sensitive to both operations that Lidia performs. First, after Lidia proposes her experience was relevantly similar to Enrico's (lines 17-18), Enrico confirms that his experience was indeed

similar to hers ("Well yes indeed"). ${ }^{6}$ Second, after Lidia introduces her competing perspective (her intention was not to quit drugs; lines 20-21), Enrico admits that he did not intend to quit using drugs either ("Yes well neither was mine," line 22), thereby amending his earlier claim (lines 8-9). Enrico thereby treats Lidia's mention of a personal experience as challenging his perspective on his own experience and as giving him an opportunity to correct it, if not even as encouraging him to do so. 
Rejecting the conveyed perspective. This is the second type of response displaying an orientation to both constituent operations of I-challenges. At the start of extract 5, Carlotta (client A) is recounting her weekend at home - this TC is a day center, open Monday to Friday. A friend offered to visit her, but she discouraged him from doing so (data not shown). The context preceding Carlotta's mention of her experience (lines 30-32) helps recognize its challenge import. After Carlotta gives reasons for not meeting her friend (lines 4-11), a staff member invites her to elaborate on her mood in the weekend (translated as "grumpy," mentioned by Carlotta at line 2), thereby establishing it as worthy of attention. Carlotta resists elaborating and establishes her mood as not requiring further scrutiny (lines 14 and 18-19). Another client, Grazia, supports this position (line 20). Cristina's intervention (lines 25-28) departs from Carlotta's perspective, as signaled with the turn-initial "Ma"/"But." Cristina proposes that there is a reason for Carlotta's bad mood, this being methadone reductionmethadone being a drug prescribed to help with detoxification in people with opioid dependence. Therefore, Cristina subsequently mentions her experience (lines 30-32) in the context of already established nonconcordance with Carlotta's perspective.

(5) IntV6 23:33 'Depression'

$$
\begin{aligned}
& \mathrm{Ca}=\text { client A (Carlotta) } \\
& \mathrm{Cb}=\text { client B (Cristina) } \\
& \mathrm{C}=\text { other client (Grazia) } \\
& \mathrm{S}=\operatorname{staff} \text { (Roberto, Marta) }
\end{aligned}
$$

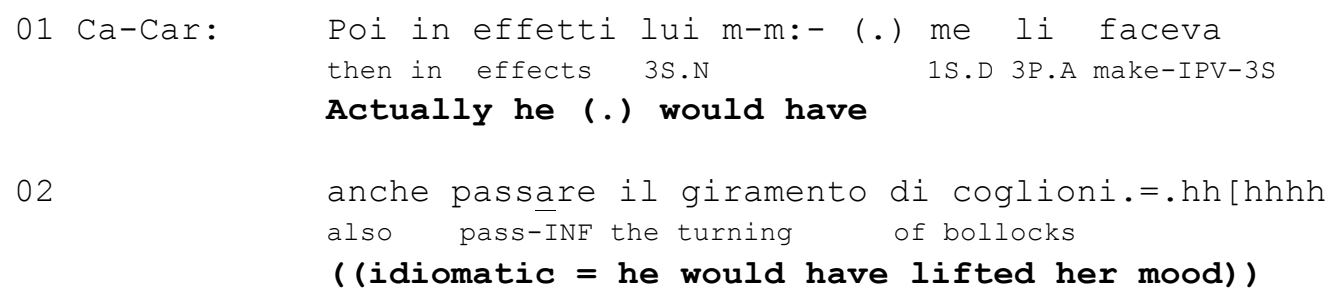


Pino, M. (2017). I-challenges: Influencing Others' Perspectives by Mentioning Personal Experiences in Therapeutic-Community Group Meetings. Social Psychology Quarterly, 80(3), 217-242.

05

06

07

08

09

$10 \mathrm{Ca}-\mathrm{Car}:$

11

12 S-Mar:

13

14 Ca-Car:

15

16 S-Mar: $\quad \uparrow A h$

PTC

$\uparrow$ Oh

17

18 Ca-Car:

19

\section{feel like talking, I didn't want to make him}

venire: (.) a casa:, mentre mangiavamo:,

come-INF to home while eat-IPV-1P

come over (.) to my house, while we were eating,

co::n mia madre, e io e lui, che io

with my mother and 1S.A and 3S.A CMP 1S.N

wi::th my mother, and me and him, while I

non avevo voglia di: .hhhh

not have-IPF.1S desire to

didn't feel like. hhhh

socializza: hre.

socialize-INF

sociali:hzing.

$(0.2)$

'Perciò: (0.4) (ho detto) ${ }^{\circ}$ (.)

therefore have-1S say-PSTP

${ }^{\circ}$ Therefore $(0.4)$ (I said) ${ }^{\circ}$ (.)

ti conviene evitare questa scenetta: che: (1.4)

2S.D be.convenient-3S avoid-INF this scene-DIM REL

it'll best for you to avoid this little scene that (1.4)

Ma non ho capito come mai avevi

but not have-1S understand-PSTP how never have-IPF.2S

But I didn't understand why you were

i coglioni girati?

the bollocks turned

$(($ idiom $=$ grumpy $))$ ?

No non c'era un motivo.

no not EX=be-IPV.3S a reason

No there wasn't a reason.

$(0.4)$

(1.1)

A:vevo voglia di stare

have-IPF.1S desire to stay-INF

I wanted to stay

[ (per i cazzi miei)

(for the dicks my)

$($ (idiom $=$ alone $)$ ) 


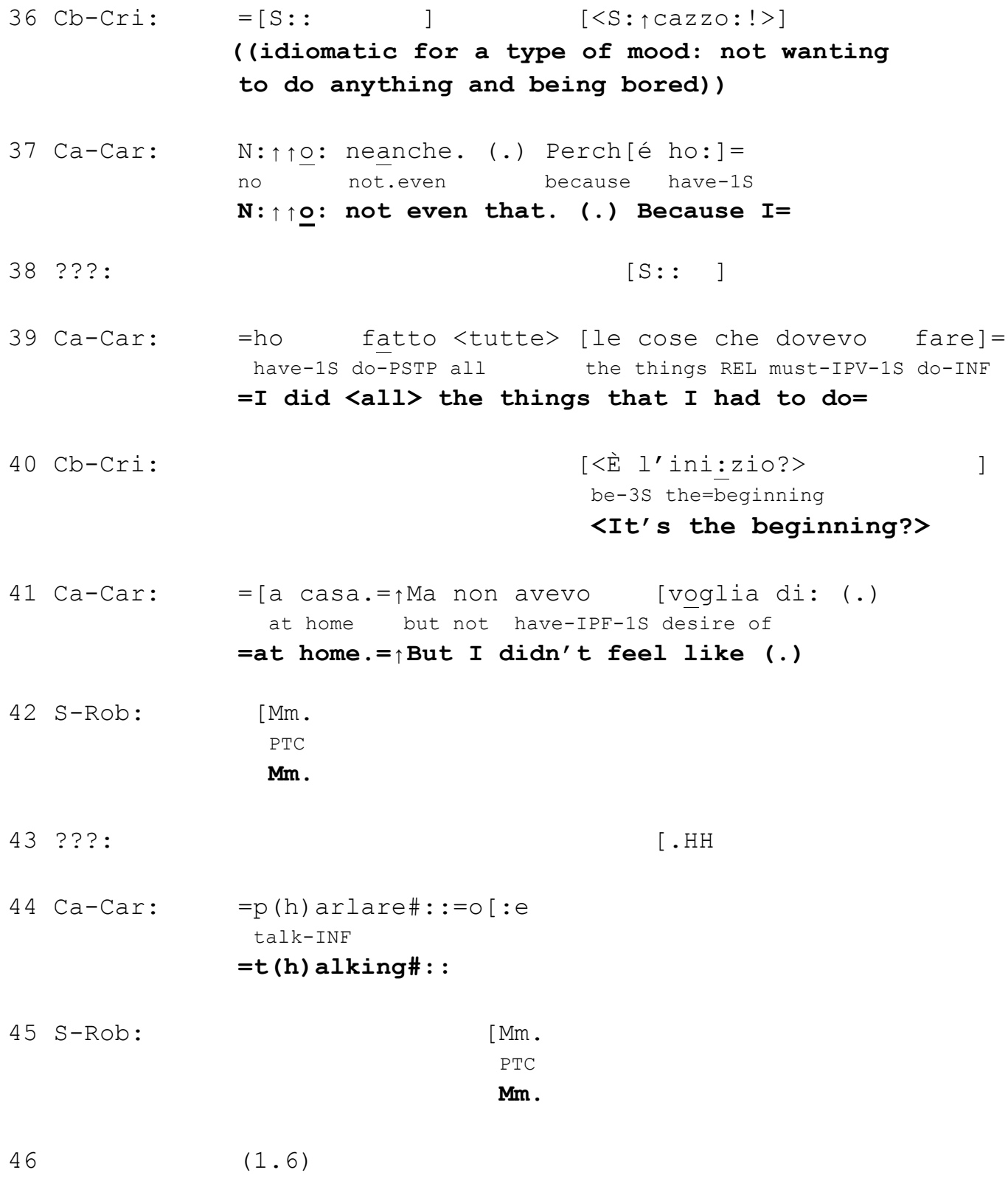

Cristina's mention of her experience (lines 30-32) implements an I-challenge through the two operations found in extracts 3 and 4 . She proposes her experience was relevantly similar to Carlotta's - she also went through methadone reduction (lines 30-31). Then she expresses a perspective that radically differs from Carlotta's "no-problem" perspective on her own experience. As a result of methadone reduction, Cristina was in a "state of depression" (line 32). Carlotta's responses are visibly sensitive to these operations. First, Carlotta treats Cristina's turn as proposing that Cristina's experience is relevantly similar to Carlotta's by contesting that relevant similarity (line 33); Carlotta is taking six milligrams of Methadone, whereas Cristina was taking a lower dose (line 31). Second, Carlotta treats Cristina's turn as expressing an alternative perspective on the experience of methadone reduction and as 
extending its applicability to Carlotta's case; Carlotta displays this understanding by rejecting the idea that she has depression (line 34).

Extracts 6 and 7 further illustrate recipients' orientations to both constituent operations of I-challenges through rejections. In extract 6, Carlotta (client A) conveys that it is desirable to smoke in her bedroom - although her mother does not allow her to do so (lines 1-18). Cristina (client B) challenges this by mentioning her experience ("I can't stand sleeping in the same room where I smoke," lines 21-23). As in extract 5, Carlotta treats this as proposing that Cristina's perspective — that is, finding the smell of smoke unpleasant — could or should apply to her case by rejecting that applicability ("No no I really don't feel it," line 25) and thereby maintaining her earlier position. Additionally, Carlotta orients to the conveyed relevant similarity of Cristina's experience by proposing that it is actually not relevantly similar; Cristina might find smoke distasteful because she is pregnant (line 31).

(6) IntV7 14:20 'Smoking'

$$
\begin{aligned}
& \mathrm{Ca}=\text { client A (Carlotta) } \\
& \mathrm{Cb}=\text { client B (Cristina) } \\
& \mathrm{S}=\operatorname{staff} \text { (Annamaria, Roberto) }
\end{aligned}
$$

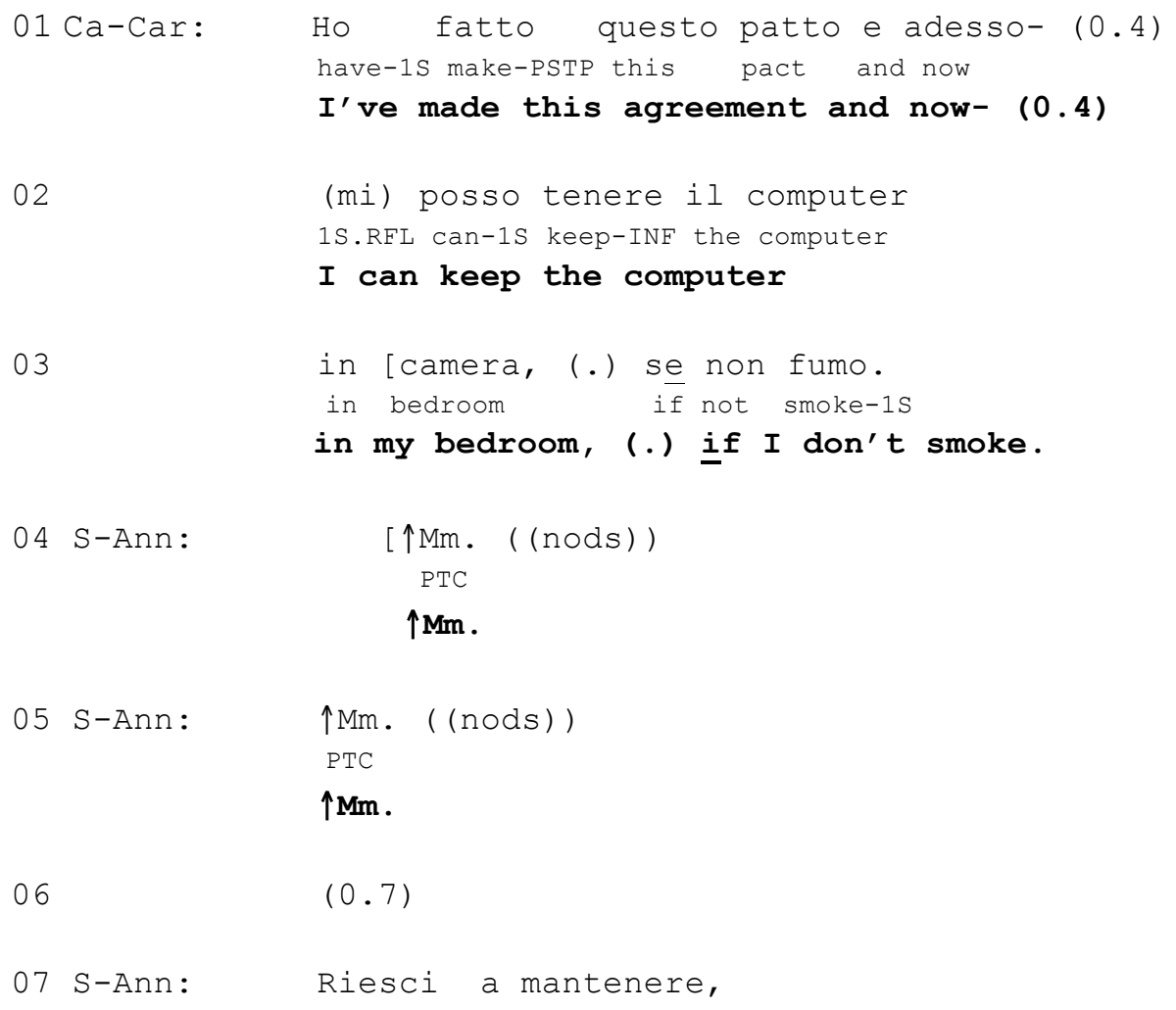


Pino, M. (2017). I-challenges: Influencing Others' Perspectives by Mentioning Personal Experiences in Therapeutic-Community Group Meetings. Social Psychology Quarterly, 80(3), 217-242.

manage-2S to maintain

Do you manage to maintain,

08

$(\cdot)$

09 Ca-Car:

. h $\quad[\mathrm{Si} \uparrow::$.

yes

.h Ye $\uparrow:: s$.

10 S-Ann:

[ l' accordo.

the=agreement

the agreement.

11

$(0.7)$

12 Ca-Car:

Più o meno sì.

more or less yes

More or less yes.

13 Ca-Car: Va be $:$ h l'importante è fumare la

PTC PTC the=important be-3s smoke-INF the

Well the important thing ((for me)) is to smoke

14

mattina appena [sveglia e la sera?

morning as.soon.as awake and the evening

in the morning when I wake up and in the evening?

15 S-Ann:

$[\mathrm{Mm}$

PTC

$\mathrm{Mm}$

(1. 7)

17 Ca-Car:

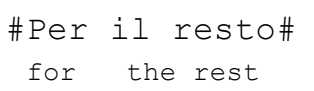

\#As for the rest\# (0.6) it's warm I can go $\uparrow$ out

18

non è più inve[rno che:

not be-3s anymore winter that

it's not winter anymore where

19 S-Ann: $[\mathrm{Mm}$

PTC

$\mathrm{Mm}$.

20

Infatti, pesa meno ade[sso.

indeed be.heavy-3s less now

Indeed, it's less of a problem now

21 Cb-Cri: ->

[Io non posso
1S.N not can-1S
I can't

22 
Pino, M. (2017). I-challenges: Influencing Others' Perspectives by Mentioning Personal Experiences in Therapeutic-Community Group Meetings. Social Psychology Quarterly, 80(3), 217-242.

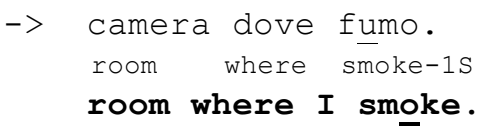

27 Cb-Cri:

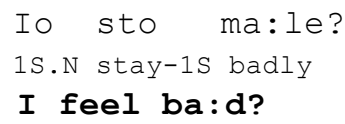

31 Ca-Car:

$$
\begin{array}{lll}
\text { Ma adesso che sei in] } \uparrow \text { ci:nta. } \\
\text { but now }
\end{array}
$$

But now that you are $\uparrow$ pre:gnant.

32 S-Rob:

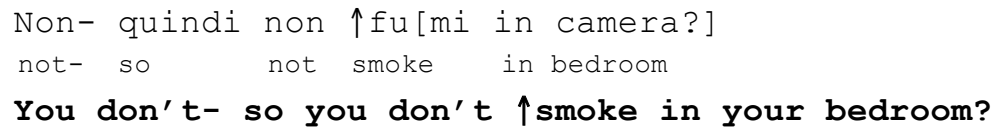

$33 \mathrm{Cb}-\mathrm{Cri}$ :

$\begin{array}{cc}\text { [No: } & \text { ] } \\ \text { no } & \text { always } \\ \text { No: } & \text { always? }\end{array}$


53 Ca-Car:

54

55 Ca-Car:

$$
(0.9)
$$

No: $n$ la sento.

not 3S.A feel-1s

I don't feel it.

$(2.0)$

hEccoh?

that's.it

hThat's ith?

Extract 7 contains another part of the debate on the Test from which extract 2 was taken. Ilario (client A) has dismissed the importance of the Test by reporting that when he went home for his Test, he did not feel he was at risk of relapsing (data not shown). He further conveys this perspective at lines $1-6$ by dismissing the significance of meeting "the same people" in his neighborhood, that is, drug addicts and drug dealers (the group members have been discussing risks associated with those encounters as occasions/triggers for relapse). Two staff members challenge this perspective (lines 9-44); they take Ilario's claim as indication that he does not recognize having a "problem," that is, addiction. In this context of emerged nonconcordance, Luigi (client B) mentions a personal experience (from line 47). His perspective contrasts with Ilario's perspective; not only did Luigi feel bad during his first Test, but he also relapsed (lines 55-56 and 64). A staff member treats Luigi's experience as challenging Ilario's perspective by conveying that Ilario should also be worried about the risk of relapsing (lines 50, 54, and 66). Crucially, Ilario treats Luigi's mention of his own experience as proposing that the same perspective should apply to him, which he rejects ("No I didn't feel like that," line 57; a very similar response to extract 6 , line 25$)$.

(7) IntL4 1:26:19 'Test'

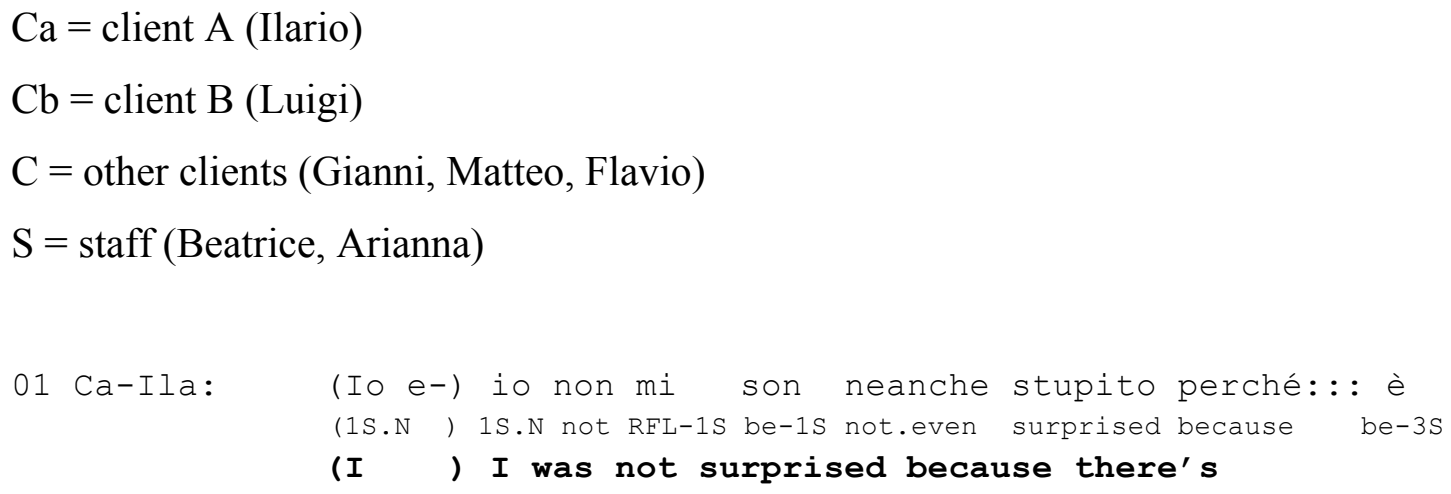


Pino, M. (2017). I-challenges: Influencing Others' Perspectives by Mentioning Personal Experiences in Therapeutic-Community Group Meetings. Social Psychology Quarterly, 80(3), 217-242.

02

03

04 Ca-Ila:

05

06 Ca-Ila:

07 C-Gia:

08

09 S-Bea:

10

11 S-Bea:

14 S-Bea:

16 C-Mat:

17 S-Bea:

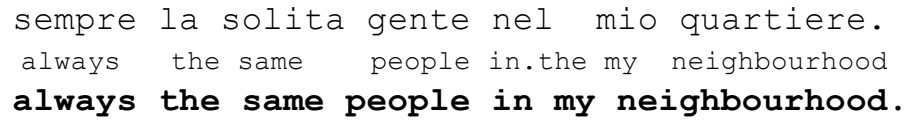

Son sempre lì eh. be-3P always there PTC

They are always there you see.

Sì ho capito.

yes have-1S understand-PSTP

Yes I get that.

$($. )

Okay. Sentiamo quello che ha detto Arianna. okay hear-IMP.1P that which have-3S say-PSTP NAME

Okay. Let's listen to what Arianna has said.

$(0.4)$

Prima di tutto, devo sapere di avere

first of all must-1s know of have-INF

First of all, I need to know that I have

un problema.

a problem

a problem.

$(0.9)$

Punto.

full.stop

Full stop.

$(0.6)$

Chiaro. Se no:, (0.2) nie [nte.

clear if no nothing

of course. Otherwise, (0.2) nothing.

[Che non è solo

which not be-3s only

Which is not only

il: "posso avere voglia" o meno.

the can-1S have-INF desire or less

the: "I can have desire" ${ }^{5}$ or not. 
Pino, M. (2017). I-challenges: Influencing Others' Perspectives by Mentioning Personal Experiences in Therapeutic-Community Group Meetings. Social Psychology Quarterly, 80(3), 217-242.

$(0.6)$

20 S-Bea:

Perché quello è [l'ultimo] forse dei problemi.

because that be-3S the=last maybe of=the problems

Because that is perhaps the last of the problems.

21 C-Gia:

[No: no. ]

no

No: no.

$(0.8)$

23 C-Gia:

Quello ti viene dopo. Dopo-

that 2S.D come-3S afterwards then-

You get that later. Then-

24

cioè: $[:::=m:: \#]$

I. mean

I mea: : $\mathrm{n}=\mathrm{m}:$ :\#

25 S-Ari:

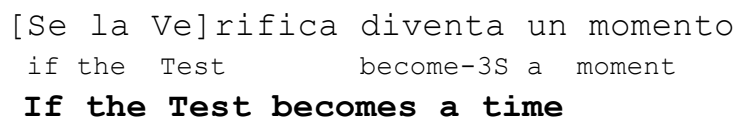

29 S-Ari: Perché è il momento in cui hai nel piatto because be-3s the moment in which have-2s in=the plate

Because it's the time where you have in your plate

sei mesi,

six months

six months,

32 S-Bea :

$\mathrm{Mm} \mathrm{mm} \mathrm{mm.}$

PTC PTC PTC

Mm $\mathrm{mm}$ mm.

33 S-Ari:

ti danno il contentino per[ché hai] la=

2S.D give-3P the sweetener bacause have-2S the

they try to make you happy because you have the=

34 Ca-Ila:

[Sì: : . ] 
Pino, M. (2017). I-challenges: Influencing Others' Perspectives by Mentioning Personal Experiences in Therapeutic-Community Group Meetings. Social Psychology Quarterly, 80(3), 217-242.

$$
\text { Ye: : s. }
$$

35 S-Ari:

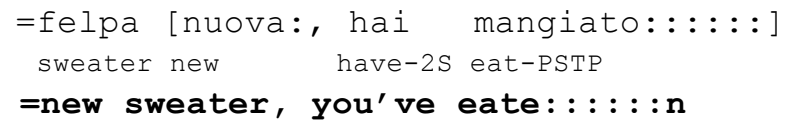

36 Ca-Ila:

[Tua madre che ti fa i tortellini di Giova]nni Rana. you mother who 2S.D make-3S the tortellini of BRAND-NAME

Your mother makes Giovanni Rana tortellini for you.

37 S-Ari:

Quello [che vuoi te::, ]

that which want-2S $2 \mathrm{~S} . \mathrm{N}$

(0.4) però: (.) lì è una vaca:nza.

Whatever,

however there be-3s a holiday

(0.4) but (.) then it's a holiday.

38 C-Fla:

[Mffg heh heh! ]

Mffg heh heh!

39 Cb-Lui:

Beh [va bene anche qu^ello però ci s:ta di [ (meno)

well go-3S well also that however EX stay-3S of (less)

Well that's also fine but ((idiom = it's not great))

40 Cli:

41 S-Ari:

[ ( Lì è come-)

(there be-3s as-)

(There it's like-)

42 S-Ari:

[VA BENE ANCHE QUELLO, MA DEVE ARRI[VARE- ]

go-3S well also that but must-3S arrive-INE

THAT'S ALSO FINE, BUT IT MUST COME-

43

[( (several indistinct voices))

44 S-Bea :

[Ci: sta]: :

EX stay-3S

That's fine.

45 ???:

Fa parte anche

make-3s part also

It's also part

46

[della Verifica. ]

of $=$ the Test

of the Test.

47 Cb-Lui: $->$
[( stavo male)] quando sono uscito le [prime= stay-IPF.1S badly) when be-1S go.out-PSTP the first
felt bad) when I went out the first=

48 S-Ari:

[Eh.

PTC

Right.

49 Cb-Lui: -> =volte. Non stavo be [ne.

times not stay-IPF.1s well 
Pino, M. (2017). I-challenges: Influencing Others' Perspectives by Mentioning Personal Experiences in Therapeutic-Community Group Meetings. Social Psychology Quarterly, 80(3), 217-242.

=times. I did not feel well.

50 S-Ari:

[Eh. [Vedi?

PTC see-2S

Right. You see?

$51 \mathrm{Cb}-\mathrm{Lui}$ :

[Assolutamente.= absolutey

Absolutely.=

52

=Non volevo nemmeno uscire.

not want-IPF.1S even go.out

$=I$ didn't even want to go out.

53

$($. )

54 S-Ari:

Ve [di?

see-2S

[Tutti (dovevamo)]

You see?

all (have-IPF.1P)

We all (had to)

55 Cb-Lui:

[Visto che la pri[ma uscita mi ]

seen that the first time.out 1S.RFL

Given that the first time ((I went)) out I

56

$\operatorname{son}([)$
$\operatorname{be}-1 \mathrm{~S}(\mathrm{)})$
$\operatorname{was}(\quad)$

57 Ca-Ila:

[No io non mi sento cosìio. no 1S.N not 1S.RFL feel-1S so 1S.N

No I don't feel like that.

58

$(0.2)$

59 Cb-Lui:

Eh $[(n \circ)$

PTC (no)

Right (no)

60 Ca-Ila:

[Quando vado a casa [in Verifica. ]
when go-1s to home in Test

When I go home for a Test.

$61 \mathrm{Cb}-\mathrm{Lui}$ :

[Io non ho ne] ssuno
1S.N not have-1S nobody
I don't have anyone

62

che mi controlla. Come Guido.

who 1S.A control-3S like NAME

to control me. Like Guido.

63

(1.1) ((indistinct talk in the background))

64 Cb-Lui: E difatti la prima uscita pa:n. (0.2) Heh.

and in.fact the firts time.out ITJ

And indeed at the first time out ba: $\mathrm{m}^{6}$. (0.2) Heh. 
Pino, M. (2017). I-challenges: Influencing Others' Perspectives by Mentioning Personal Experiences in Therapeutic-Community Group Meetings. Social Psychology Quarterly, 80(3), 217-242.

65

66

67

$68 \mathrm{Cb}-\mathrm{Lui}$ :

70 S-Ari:

71

72

$\mathrm{Cb}-\mathrm{Lui}$ :
$(0.5)$

Vedi?

see-2S

You see?

$(0.4)$ h. E::::: le uscite dopo:: han dovuto

PCT and the times.out then have-3P need-PSTP

Right. A: : : : : nd then the next times they had to

spingermi fuori per[ché

push-INF=1S.A out because

to push me out because

[Mh $\mathrm{n}(\mathrm{h})$ on $\mathrm{V}(\mathrm{h})$ olevi andarci.

not want-IPF-2S go-INF=LOC

Mh you $d(h) i d n^{\prime} t w(h)$ ant to go.

$(0.6)$

Eh perché al mio paese: c'è

PTC because at.the my village $\mathrm{EX}=\mathrm{be}-3 \mathrm{~S}$

Eh because in my village there's

73

$(g e: n)$

(people)

(peo)

$74 \mathrm{~S}-?:$

75

$\mathrm{Cb}-\mathrm{Lui}$ :

[cioè

I.mean

I mean

76

$($. )

$77 \mathrm{Cb}-\mathrm{Lui}$ :

e:h non è semplice. Non ho nessuno

PTC not be-3s simple not have-1s nobody

e:h it isn't easy. I've got no-one

78

che mi cont(ro)- .hh cioè se decido: : : lo

who 1S.A control

I.mean if decide-1s

to control me .hh I mean if I decide I

79

fa[ccio. Non è che:

do-1s not be-3s that

do it. It's not that

80 Ca-Ila?:

$\left.\begin{array}{l}\text { Sì }( \\ \operatorname{yes}(\end{array}\right)$

81

ma è (a) 
Pino, M. (2017). I-challenges: Influencing Others' Perspectives by Mentioning Personal Experiences in Therapeutic-Community Group Meetings. Social Psychology Quarterly, 80(3), 217-242.

but be-3s (at)

but it's ( )

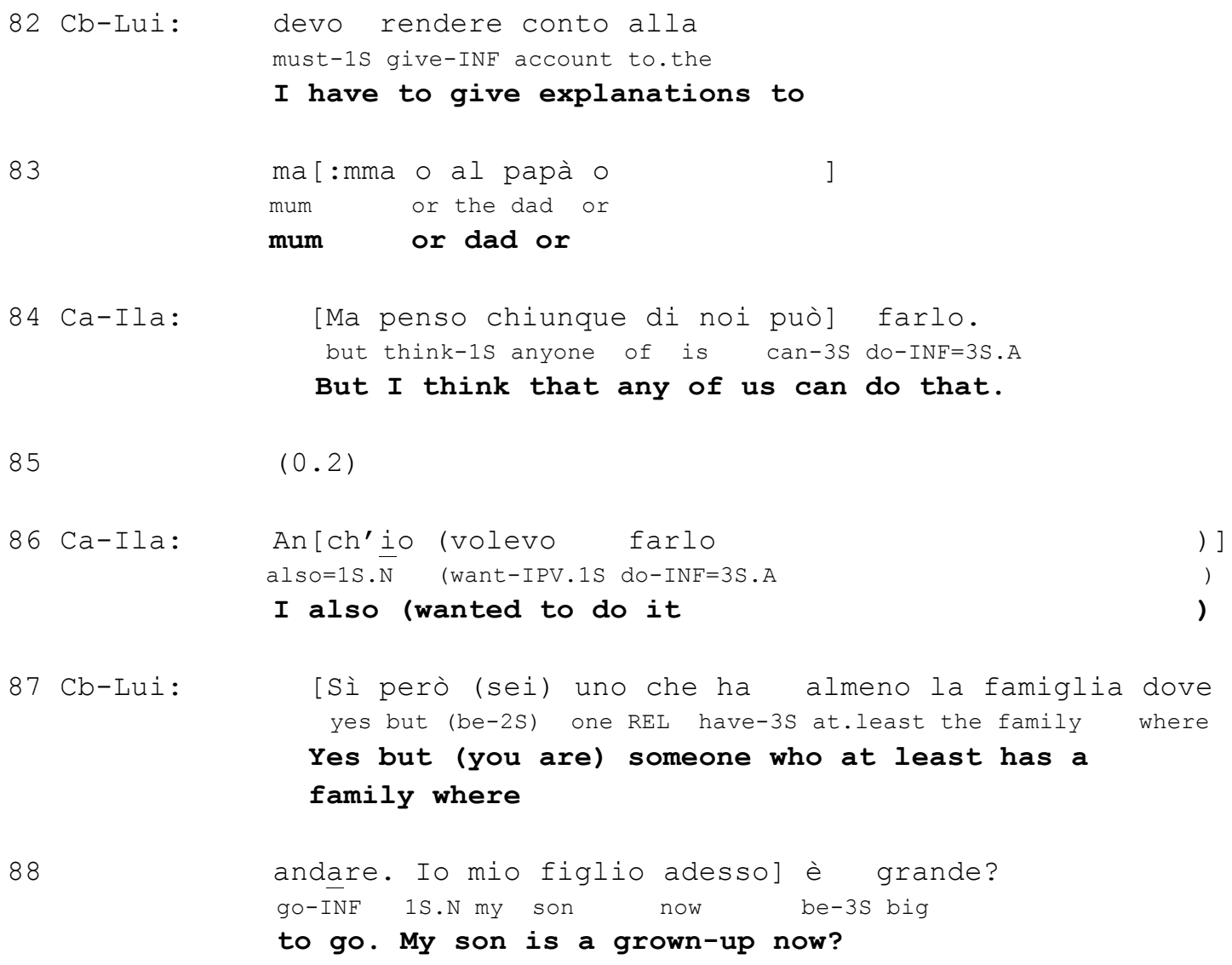

Testing and contesting similarity. I turn now to cases where client A orients to the first constituent operation of I-challenges (relevant similarity) but not the second (competitive perspective).

In extract 4, Cristina challenges Mauro's perspective on the meaning of his legs spasm. Mauro orients to Cristina's conveyed proposal that her experience was relevantly similar to his; he tests its relevant similarity by asking whether she experienced spasms when she was in withdrawal (line 11). Cristina defends her position by suggesting (through the emphatically delivered " $\uparrow \downarrow \downarrow o$ " at line 14) that although she was not in withdrawal, her experience is nevertheless relevantly similar to Mauro's precisely because he is not in withdrawal either. This aspect connects to the second operation of Cristina's turn, that is, the normalizing account - and challenge - it conveys. Mauro's response ("Boh"/“I don't know," line 16) may display his understanding that Cristina has offered her experience as a resource he can use to reevaluate his own experience; that is, "I don't know" may acknowledge that he should do something with her experience but that he "does not know" how. However, unlike the clients in the previous examples, Mauro's response does not display a clear orientation to a conveyed 
Pino, M. (2017). I-challenges: Influencing Others' Perspectives by Mentioning Personal Experiences in Therapeutic-Community Group Meetings. Social Psychology Quarterly, 80(3), 217-242.

challenge. For instance, he does not revise his perspective (as Enrico does in extract 3), nor does he reject the applicability of client B's alternative perspective to his own case (as the clients in extracts 2, 5, 6, and 7 do). Nevertheless, Cristina pursues Mauro's acceptance of an alternative perspective on his symptoms. She proposes that his symptoms are "little twitches" and therefore benign (lines 18 and 21; another client does the same at lines 19-20). This retrospectively suggests that Cristina may have mentioned her experience as a first attempt at proposing an alternative perspective on Mauro's symptoms.

One possible explanation for client A's response in extract 4 is that with I-challenges, B does not directly criticize A's perspective. Rather, B comments on their own experience in contrastive terms, and they exploit the syllogistic procedure examined in the previous section to convey the applicability of that competitive perspective to A's case. The challenge import of B's turn is available for A to infer and act on, with the implication that A may fail to do so. However, there is another possibility; A's practice of testing the relevant similarity of B's experience (seen in extract 4, line 11) is present in other cases. This suggests that this response may be, in itself, a recurrent practice for responding to I-challenges and that its presence may reflect A's orientation to the challenge import of B's mention of a personal experience.

In extract 6, Carlotta tests the relevant similarity of Cristina's experience (line 31) by suggesting that Cristina's experience of disliking the smell of smoke is caused by her pregnancy-Carlotta is not pregnant. Carlotta does so after rejecting the applicability of Cristina's perspective to her case (lines 25 and 29) and after Cristina has reissued her Ichallenge (lines 27 and 30). In this context, the practice of testing the relevant similarity of Cristina's experience is a way of undermining the challenge conveyed by mentioning that experience. Extract 5 further supports this possibility; Carlotta challenges the relevant similarity of Cristina's experience (line 33) and subsequently rejects the applicability of the perspective conveyed by mentioning that experience (line 34).

These cases show client A challenging the relevant similarity of their own and B's experiences in cases where they also reject the applicability of B's conveyed perspective to their own case. This raises the possibility that A may be doing the same in cases where they do not overtly contest the applicability of the competing perspective, but they test or contest the relevant similarity of their own and B's experiences. Mauro does so in extract 4 (line 11). Extract 8 presents a similar pattern. Manolo (client A) has relapsed into heroin use a few days before the group meeting (Cristina raises this at lines 25-26); he provides a generic explanation for why this has happened (he was "out of his mind," lines 38-40). Cristina (client B) challenges this by proposing that Manolo relapsed because he is not satisfied with his life (lines 
41-45). After an objection by Manolo (lines 46-48), Cristina challenges his perspective by mentioning her own experience (lines 54-58). She refers to the fact-discussed earlier in that meeting - that he is doing several free time activities. By reporting that she does not do as many activities, she implies that her life does not offer many sources of satisfaction and that despite this, she is not using drugs. In response, Manolo contests the relevant similarity of the two experiences ("But you are stronger," line 62). By doing so he can undermine the Ichallenge; specifically, if Cristina is "stronger," her experience cannot be used as a model against which to assess Manolo's propensity to relapse into drug use.

(8) IntV6 1:03:38 'Relapse'

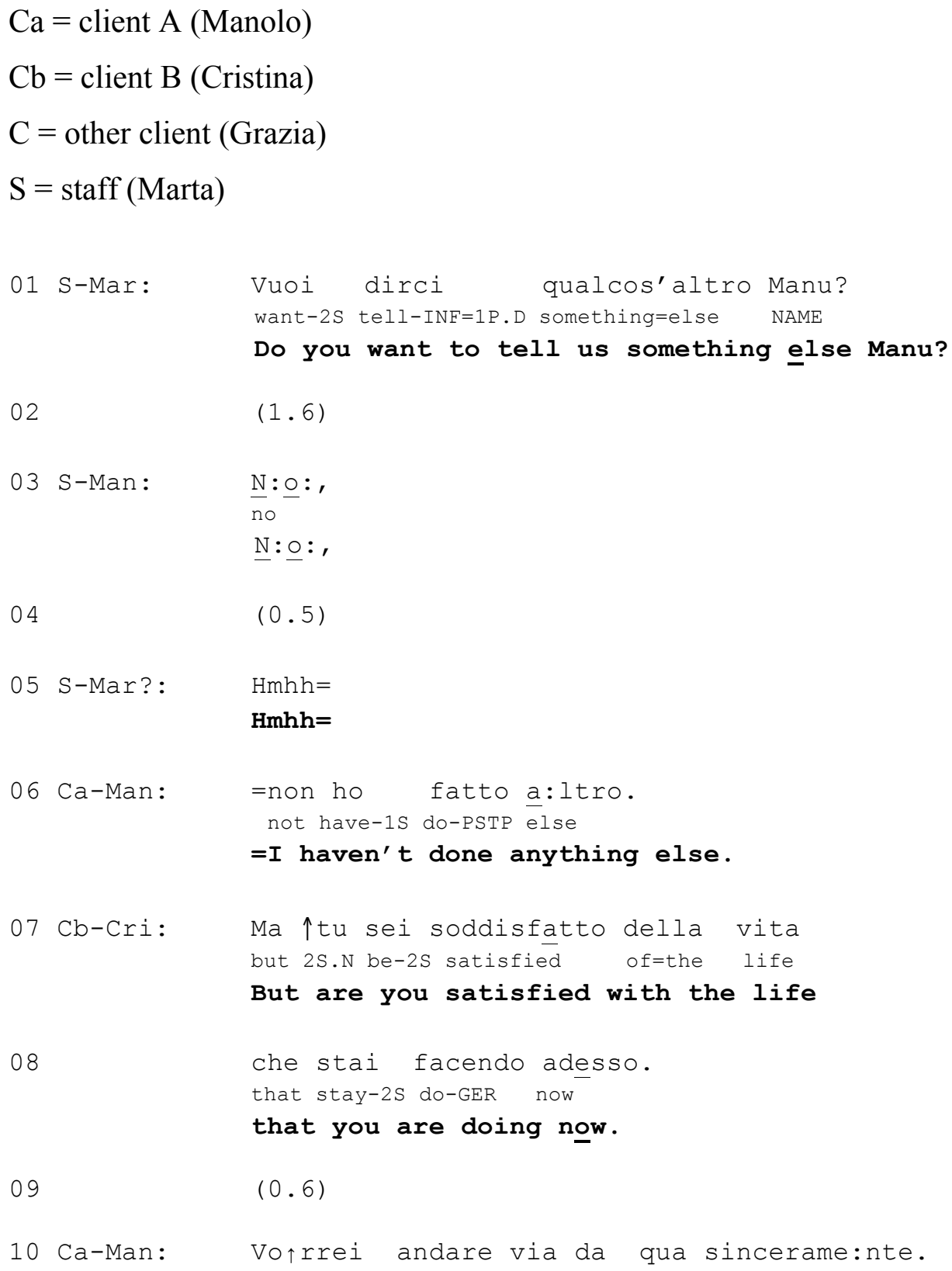


Pino, M. (2017). I-challenges: Influencing Others' Perspectives by Mentioning Personal Experiences in Therapeutic-Community Group Meetings. Social Psychology Quarterly, 80(3), 217-242.

28 Ca-Man:

$(0.8)$

$\mathrm{A}: \mathrm{h}$ bo: $\mathrm{h}$.

PTC PTC

\section{A:h I don't know.}

$(0.5)$

30 C-Gra:

Qu $\uparrow$ ando.

when

Wh^en. ((turns towards $\mathrm{Cb}-\mathrm{Cri})$ )

32 Ca-Man:

La settimana scorsa. the last week

Last week.

36 S-Mar:

tk (0.3) (Ciò: ) ?

tk (0.3) (There you go)? ((looking at C-Gra))

Mah bo:h \#pe:rché::\# (.) m::h=ogni ta:nto

PTC PTC because PTC every while

Well I don't know \#because\# (.) $\mathrm{m}: \mathrm{h}=$ every once in while

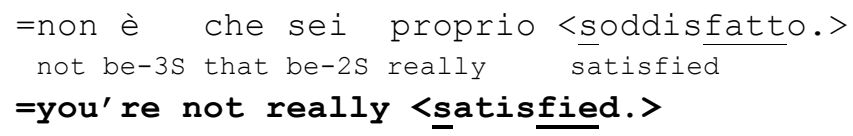


Pino, M. (2017). I-challenges: Influencing Others' Perspectives by Mentioning Personal Experiences in Therapeutic-Community Group Meetings. Social Psychology Quarterly, 80(3), 217-242.

44

45

46 Ca-Man:

47

48 Ca-Man:

50

51 Cb-Cri:
(1.0) >secondo me< ti manca

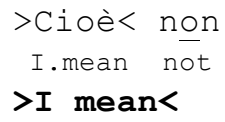


Pino, M. (2017). I-challenges: Influencing Others' Perspectives by Mentioning Personal Experiences in Therapeutic-Community Group Meetings. Social Psychology Quarterly, 80(3), 217-242.

60

61 ???:

62 Ca-Man:
$(0.9)$

$(\mathrm{Tkl})$

Però tu sei più fo:rte.

but 2S.N be-2S more strong

But you are stro:nger.

\section{I-Challenges and the Problem of Experience}

Previous research in conversation analysis has found that speakers treat each other's subjective experiences as areas where everyone has special "entitlements" (Peräkylä and Silverman 1991; Sacks 1984). This means that everyone can usually claim that they are more knowledgeable than others about their own experiences and therefore more entitled to make claims about them. The activity of challenging a peer's perspective raises a "problem of experience" (Heritage, 2011); TC clients are vulnerable to be heard as making unjustified claims on matters of which they do not have first-hand knowledge. Recipients can always object that they know more about their own experience.

Navigating the problem of experience. I-challenges seem especially fitted for navigating the problem of experience. With them, clients only make claims about their own case. To appreciate this, it is useful to consider instances where clients start with a different practice and then switch to an I-challenge.

In extract 3, Lidia (client B) starts a possible challenge by referring to what "most people" do (line 15). She abandons this utterance in progress and switches to mentioning her experience (line 17). The claim about "most people" may already be designed to navigate the problem of experience; "most people" is not "everyone," and therefore this reference form already allows for the possibility that Enrico belongs to the few people to whom the claim does not apply. However, by switching to mentioning her own experience, Lidia avoids any claim that might be heard as being "about" Enrico's experience. She makes a claim about her own experience and leaves it to Enrico to extract implications for himself.

In extract 2, Gianni (client B) challenges his peers' perspectives with a general claim (lines 1-4). Another client treats this precisely as a general claim applicable to the clients, which he does by rejecting its validity ("But that's not true," line 8) based on his personal experience - that is, an area of knowledge over which he can clam higher entitlement ("I didn't feel [...]," line 8). Here, Gianni's general claim has raised a problem of experience and has 
been rejected on that basis. Later, Gianni switches to his own experience as a basis for his challenge (lines 28-32). Another client rejects Gianni's challenge but in a different way than the previous client (at line 8). By saying, "Well for me it was the same as before" (lines 3334), this client does not treat Gianni's turn as making a claim about the other clients' experiences but rather - and consistently with the analyses reported in the previous sectionas offering Gianni's experience as a model for others to reconsider the meaning of their own experiences.

I-challenges are particularly advantageous because with them TC clients avoid making claims about their peers' circumstances, therefore navigating the problem of experience that this activity raises. In doing this, TC clients also achieve two important and closely related outcomes: they give a basis for the challenge, and they promote relational affiliation (Figure 1).

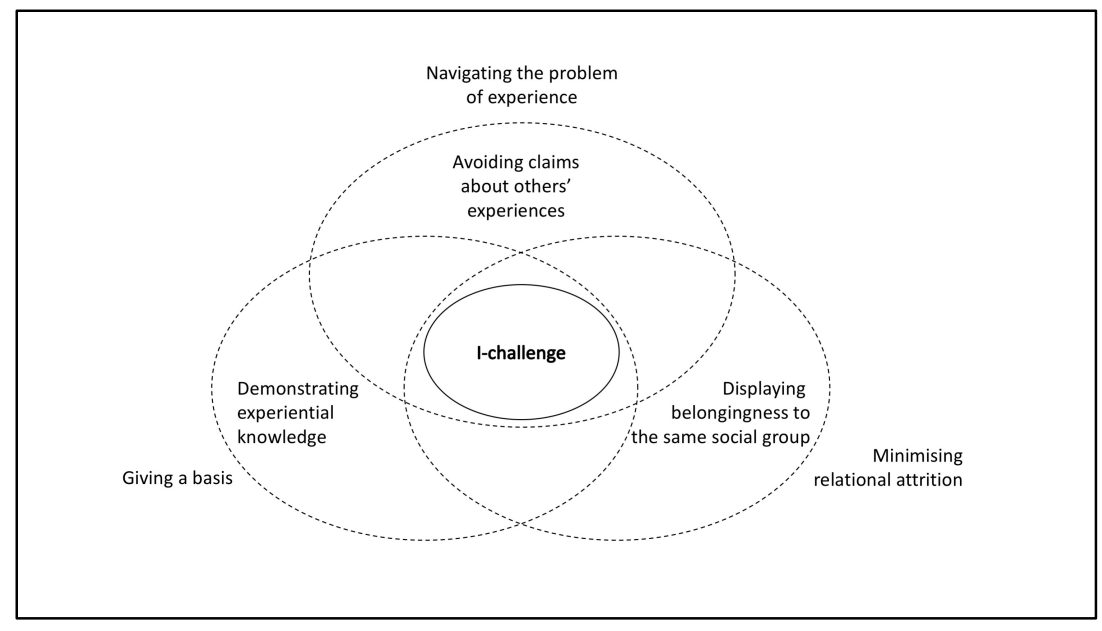

Figure 1 - I-challenges and the problem of experience

Giving a basis. In a study on how people describe the bases for their knowledge, Pomerantz (1984:609) observed that "when people are concerned with being accountable for what they say, they may mitigate their accountability by presenting sources or bases for believing particular states of affairs, without accountably asserting the states of affairs that are suggested [emphasis added]" (see also Bolden and Mandelbaum 2017). Similarly, mentioning a personal experience enables TC clients to implement a challenge and provide a basis for it concurrently 
Pino, M. (2017). I-challenges: Influencing Others' Perspectives by Mentioning Personal Experiences in Therapeutic-Community Group Meetings. Social Psychology Quarterly, 80(3), 217-242.

(through the same action). This allows clients to challenge their peers without commenting on their experiences and support the challenge with the weight of experiential knowledge.

Minimizing relational attrition. Challenging someone's perspective has disaffiliative relational implications. It has the potential of undermining the sense of solidarity that can stem from belonging to the same group. With I-challenges, clients compensate for this by displaying belongingness to the same social group (Arminen 2004).

The I-challenge is based on client B's proposal that they have an experience in common with client A. This operation reflexively characterizes the clients as members of a social group sharing the same relevant experiences, including a history of drug use and undergoing treatment. Unlike alternative practices for challenging others (e.g., criticizing; Pino 2016a), Ichallenges convey that modifying one's own perspective can be beneficial for both the recipient and the speaker. There is a conveyed sense of "being in the same boat." With Ichallenges, clients make relevant an aspect of their social relationship in their talk (Raymond and Heritage 2006).

At the same time, a claim of shared experience helps clients add force to the challenge. Although with I-challenges clients only comment on their own experience, the applicability of that claim extends beyond their own individual case. This is because clients construct their case as representative of a class of experiences, of which the recipient's experience is also an instance. For example, in extract 4, line 7, Cristina conveys that her experience does not tally with Mauro's conveyed perspective on his leg spasms. She conveys that there exists at least one case in the world - her own — where things did not quite work in the way that Mauro has described (Drew 1992). On this basis, Cristina's experience has implications for anyone who made the sorts of claims that Mauro has made and who were in a similar situation. This is evidenced by another client joining in and supporting the alternative perspective (line 19) and by Cristina seeking further confirmation from that client (line 21).

In summary, I-challenges enable clients to navigate the problem of experience by way of avoiding claims about their peers' circumstances. By mentioning their experience, clients concurrently provide a basis for the challenge and claim belongingness to the same social group, thereby reducing the disaffiliative implications of their challenges.

\section{Discussion}


Social influence has been a central topic in social psychology from its inception. It is encapsulated in Allport's (1985:3) definition of the field as "the attempt to understand and explain how the thoughts, feelings, and behaviors of individuals are influenced by the actual, imagined, or implied presence of other human beings." Typically, social psychologists have explained social influence with reference to how recipients cognitively process message-based persuasion and other forms of influence (Petty and Briñol 2008; Wood 2010). This line of inquiry has been somewhat silent to how people practically realize influence through social actions at the ground level of their conversational interactions.

The study reported here shows how it is possible to explore social influence from a different perspective, using conversation analysis. Rather than trying to infer the cognitive processes of message recipients, I focused on the structure and function of communicative practices that speakers use to exert social influence. I examined TC group meetings for people recovering from drug misuse - a setting where influencing people's perspectives is an especially consequential activity-and focused on how clients challenge their peers' perspectives on their own experiences. Through close examination of when, within their interactions, TC clients use specific communicative practices and how they design them, I identified situated choices they make by selecting a practice — an utterance referencing the self or I-challenge - over other available practices to implement the social action of challenging a peer. Rather than explaining these choices with reference to how $\mathrm{TC}$ clients might orient to (e.g., anticipate) their peers' cognitive responses, I proposed that TC clients design their actions by taking into consideration constraints associated with the very nature of the social activity in which they engage — challenging a peer's perspective - and the practical problems that it raises. This perspective augments existing social psychological notions of influence with insights on the social organization of influence as a practical activity in which people engage in their interpersonal interactions.

The findings suggest that there are at least two broad approaches to influencing other people's perspectives: direct versus indirect. TC clients implement a direct approach to influence when they claim to know about aspects of their peers' experiences and associated meanings and feelings (see extract 2). With the indirect approach-embodied in the Ichallenge - clients make claims about a different matter (i.e., not about their recipients' experiences) in a way that carries implications for how recipients can make sense of their own experiences (cf. Pino 2016a).

The demarcation between direct and indirect approaches to influence does not only apply to challenges but to other social actions as well. For example, in the case of requests for 
assistance, people can directly nominate a recipient to perform a particular action; alternatively, they can report a need or a desire and leave it to recipients to volunteer assistance (Kendrick and Drew 2016; Pino 2016c). With these approaches, speakers establish different social expectations for recipient responses, and they also propose different kinds of social relationships in the moment-by-moment unfolding of speaker-recipient interactions.

The two approaches to influence have received some attention within interventionist approaches to social influence - a popular example being nudge theory (Thaler and Sunstein 2009). Within that framework, the direct approach to influence translates into promoting behavioral changes through injunctions or restrictions of people's options for action. The indirect approach translates into designing physical spaces and social environments in ways that maximize the probability of desired behavioral outcomes. In this article, I have shown that speakers orient to the availability of these two approaches, their interactional consequences, and their relational implications at the ground level of their conversational exchanges. With Ichallenges, TC clients make available a resource - their own experience - that recipients can use to modify their own perspectives without inviting them to do so. TC clients thereby "design" conversational environments that can be conducive to a certain behavioral outcome without formally soliciting it. These findings also support and substantiate Thomas Gordon's early intuition about the different affordances and implications of I-messages as opposed to you-messages.

The findings resonate with the social psychological notion that ensuring satisfactory relations with others is a powerful motive driving how people respond to social influence (Wood, 2000). Social psychologists have mainly used this notion to explain how recipients respond to social influence. By contrast, my results suggest that a concern with maintaining affiliative relationships is already observably embodied in the ways in which speakers design their actions for their recipients. With I-challenges, TC clients claim belongingness to the same social group as their peers (Arminen 2004), thereby reducing the disaffiliative relational implications associated with challenging a peer's perspective. Additionally, I have shown that speakers' situated choice to employ I-challenges is a way of addressing a problem of experience (Heritage 2011) raised by the activity of challenging others; this had not been previously described in the social psychological literature on influence. In the context examined here, speakers have a particular way of maintaining positive relations with others; they avoid making claims about matters over which their recipients may justifiably claim superior knowledge (cf. Pino 2016a). 
This study has some limitations that invite caution when interpreting its findings. It is confined to one particular institutional setting; therefore, future research should explore the extent to which the findings extend to other institutional and mundane settings. Since the study did not elicit participants' thoughts after recording their interactions, there is no way of knowing whether their perspectives shifted as a result of being exposed to I-challenges. Despite these limitations, the study findings point to the power of first-person talk in conveying social influence. It also exemplifies how conversation analysis can be used to address a central topic in social psychology by examining people's practices for managing real problems in real time as well as the situated understandings that they make available to each other in the course of their naturally occurring interactions.

\section{Acknowledgments}

The author would like to thank Mara Calta (Fondazione Exodus) and Gianluigi Formaggioni (Fondazione San Gaetano) for helping collect the data and for all their support in several phases of the project; all the therapeutic community staff members and clients who appear in the recordings; as well as three anonymous reviewers for their thorough comments on an earlier version of this article. Finally, my gratitude goes to Charles Antaki and Alison Pilnick for their invaluable contributions to the analyses leading up to this article and to Charles Antaki and Kobin Kendrick for commenting on earlier versions of this article.

\section{Funding}

The author disclosed receipt of the following financial support for the research, authorship, and/or publication of this article: The research leading to these results has received funding from the People Programme (Marie Curie Actions) of the European's Union Seventh Framework Programme (FP7/2007-2013) under REA grant agreement no 626893. The contents of this paper reflect only the views of the author and not the views of the European Commission.

\section{Notes}

1. In this study, influence is broadly defined as an activity whereby a speaker aims to bring about some change in a recipient's behaviors. Perspective is defined as a way of assessing or 
Pino, M. (2017). I-challenges: Influencing Others' Perspectives by Mentioning Personal Experiences in Therapeutic-Community Group Meetings. Social Psychology Quarterly, 80(3), 217-242.

making sense of a state of affairs and is preferred in this study over attitude despite its common use in social psychology. Attitude can be taken to refer to a more stable configuration of evaluations, whereas the term perspective can accommodate transient views that group members voice with no assumption about whether they represent underlying stable cognitive patterns.

2. See Online Appendix at spq.sagepub.com/supplemental.

3. Available at: http://www.asanet.org/research-and-publications/journals/social-psychologyquarterly/social-psychology-quarterly-transcription-conventions.

4. In most cases, client $\mathrm{B}$ challenges client $\mathrm{A}$ in a context of already established nonconcordance between their perspectives. I highlight this aspect in the analyses because it helps grasp the interactional function of I-challenges. However, this does not appear to be an essential feature for the action recognition of I-challenges. Extract 6 ("Smoking") is a case where an I-challenge is not delivered in the context of already established nonconcordance.

5. This tacitly relies on shared understandings about how addicts behave. Lidia alludes to the fact that addicts usually seek a prescription of methadone when they run out of money and cannot buy the heroin they need to relieve their withdrawal symptoms (as supported by Lidia's reference to running out of money at line 18).

6. Enrico's responses at lines 14, 19, and 22 are "Beh" and "Sì beh" prefaced (see Online Appendix A), translated as "Well" and "Yes well," respectively (Heritage 2015). With these, Enrico pushes back against Lidia's challenge; that is, he does not frame his revision of his own earlier perspective as a whole-hearted perspectival shift but as a concession, partially preserving the validity of that previous perspective. With "at first" (lines 14 and 16), he concedes that he did not intend to quit using drugs when he initially approached the support service and conveys that the decision to quit came later. This feature does not change the main point of my analysis: Enrico treats Lidia's mention of her experience as making relevant a revision of his perspective on his own experience.

7. Alluding to desire for illegal drugs.

8. He alludes to a relapse into drug or alcohol use. This is confirmed by what he says later in the recorded meeting (data not shown).

References

Allport, Gordon W. 1985. "The Historical Background of Social Psychology.” Pp. 1-46 in Handbook of Social Psychology. Vol. 1, 3rd ed., edited by G. Lindzey and E. Aronson. New York: Random House. 
Pino, M. (2017). I-challenges: Influencing Others' Perspectives by Mentioning Personal Experiences in Therapeutic-Community Group Meetings. Social Psychology Quarterly, 80(3), 217-242.

Arminen, Ilkka. 2004. "Second Stories: The Salience of Interpersonal Communication for Mutual Help in Alcoholics Anonymous.” Journal of Pragmatics 36:319-47.

Bolden, Galina, and Jenny Mandelbaum. 2017. "The Use of Conversational Co-Remembering to Corroborate Contentious Claims." Discourse Studies 19:3-29.

Campling, Penelope. 2001. "Therapeutic Communities." Advances in Psychiatric Treatment 75:365-72.

Drew, Paul. 1992. "Contested Evidence in Courtroom Cross-Examination: The Case of a Trial for Rape.” Pp. 470-520 in Talk at Work, edited by P. Drew and J. Heritage. Cambridge: Cambridge University Press.

Drew, Paul. 1998. "Complaints about Transgressions and Misconduct." Research on Language and Social Interaction 31:295-325.

Drew, Paul, and Traci Walker. 2009. "Going too Far: Complaining, Escalating and Disaffiliation." Journal of Pragmatics 41:2400-14.

Gill, Virginia T., and Douglas W. Maynard. 1995. “On 'Labelling' in Actual Interaction: Delivering and Receiving Diagnoses of Developmental Disabilities." Social Problems 42:11-37.

Gordon, Thomas. 1970. P.E.T., parent effectiveness training: The tested New Way to Raise Responsible Children. New York: Peter H. Wyden.

Gordon, Thomas. [1974] 2003. Teacher Effectiveness Training. New York: Three Rivers Press. Heritage, John. 2011. "Territories of Knowledge, Territories of Experience: Empathic moments in interaction." Pp. 159-83 in The Morality of Knowledge in Conversation, edited by T. Stivers, L. Mondada, and J. Steensig. Cambridge: Cambridge University Press.

Heritage, John. 2012. "The Epistemic Engine: Sequence Organization and Territories of Knowledge." Research on Language \& Social Interaction 45:30-52.

Heritage, John. 2015. "Well-Prefaced Turns in English Conversation: A Conversation Analytic Perspective." Journal of Pragmatics 88:88-104.

Heritage, J. Forthcoming. "Epistemics, Conversation Analysis, and 'Post-Analytic' Ethnomethodology: A Rebuttal.” Discourse Studies.

Heritage, John, and Anna Lindström. 1998. "Motherhood, Medicine, and Morality: Scenes from a Medical Encounter." Research on Language and Social Interaction 31:397-438.

Jefferson, Gail. 1988. "On the Sequential Organization of Troubles-Talk in Ordinary Conversation." Social Problems 4:418-41.

Kendrick, Kobin. 2013. "The Role of Reciprocity in the Organization of Action-Sequencing." Presented at the 7th Conversation Analysis Day, Loughborough University, UK. 
Pino, M. (2017). I-challenges: Influencing Others' Perspectives by Mentioning Personal Experiences in Therapeutic-Community Group Meetings. Social Psychology Quarterly, 80(3), 217-242.

Kendrick, Kobin, and Paul Drew. 2016. "Recruitment: Offers, Requests, and the Organization of Assistance in Interaction." Research on Language and Social Interaction 49:1-19.

Leudar, Ivan, Charles Antaki, and Rebecca Barnes. 2006. "When Psychotherapists Disclose Personal Information about Themselves to Clients." Communication and Medicine 3:2741.

Oryan, Schlomit, and John Gastil. 2013. "Democratic parenting: paradoxical messages in democratic parent education theories." International Review of Education 59:113-129.

Peräkylä, Anssi, and David Silverman. 1991. “Owning Experience: Describing the Experience of Other Persons." Text 11:441-80.

Petty, Richard E., and Pablo Briñol. 2008. "Psychological Processes Underlying Persuasion. A Social Psychological Approach.” Diogenes 217:52-67.

Pino, Marco. 2016a. "Delivering Criticism through Anecdotes in Interaction." Discourse Studies 18:695-715.

Pino, Marco. 2016b. "Knowledge Displays: Soliciting Clients to Fill Knowledge Gaps and to Reconcile Knowledge Discrepancies in Therapeutic Interaction.” Patient Education and Counseling 99:897-904.

Pino, Marco. 2016c. "When Assistance Is Not Given: Disaffiliative Responses to Therapeutic Community Clients' Implicit Requests.” Pp. 674-93 in The Palgrave Handbook of Adult Mental Health, edited by M. O’Reilly and J. Parker. Basingstoke: Palgrave Macmillan.

Pomerantz, Anita. 1984. "Giving a Source or Basis: The Practice in Conversation of Telling 'How I Know.'” Journal of Pragmatics 8:607-25.

Rapoport, Robert N. 1959. Community as Doctor: New Perspectives on a Therapeutic Community. London: Tavistock Publications.

Raymond, Geoffrey, and John Heritage. 2006. "The Epistemics of Social Relations: Owning Grandchildren." Language in Society 35:677-705.

Ruusuvuori, Johanna. 2005. “'Empathy' and 'Sympathy' in Action: Attending to Patients' Troubles in Finnish Homeopathic and General Practice Consultations." Social Psychology Quarterly 68:204-22.

Sacks, Harvey. 1984. “On Doing 'Being Ordinary.” Pp. 413-29 in Structures of Social Action:

Studies in Conversation Analysis, edited by J. M. Atkinson and J. Heritage. Cambridge: Cambridge University Press.

Sacks, Harvey. 1992. Lectures on Conversation. 2 vols. Oxford: Blackwell. 
Schegloff, Emanuel A. 1988. "Goffman and the Analysis of Conversation." Pp. 89-135 in Erving Goffman: Exploring the Interaction Order, edited by P. Drew and A. J. Wootton. Cambridge, UK: Polity Press.

Schegloff, Emanuel A. 1990. “On the Organization of Sequences as a Source of 'Coherence' in Talk-in-Interaction.” Pp. 51-77 in Conversational Organization and Its Development, edited by B. Dorval. Norwood, NJ: Ablex Publishing Corporation.

Schegloff, Emanuel A. 1996. "Turn Organization: One Intersection of Grammar and Interaction.” Pp. 52-133 in Interaction and Grammar, edited by E. Ochs, E. A. Schegloff, and S. A. Thompson. Cambridge: Cambridge University Press.

Schegloff, Emanuel A. 1997. "Practices and Actions: Boundary Cases of Other-Initiated Repair." Discourse Processes 23:499-545.

Shah, Deepa, and Sarah Paget. 2006. Service Standards for Addiction Therapeutic Communities. London: Royal College of Psychiatrists.

Sidnell, Jack. 2007. “'Look'-Prefaced Turns in First and Second Position: Launching, Interceding and Redirecting Action.” Discourse Studies 9:387-408.

Sidnell, Jack, and Tanya Stivers. 2013. Handbook of Conversation Analysis. Boston: WileyBlackwell.

Thaler, Richard H., and Cass R. Sunstein. 2009. Nudge: Improving Decisions about Health, Wealth, and Happiness. New York: Penguin Books.

Wood, Wendy. 2000. “Attitude Change: Persuasion and Social Influence." Annual Review of Psychology 51:539-70. 